\title{
DE SIMULACRO A SIMULADO: O USO DO CONCRETO EM OBRAS DE LE CORBUSIER
}

\author{
DE SIMULACRO A LA SIMULACIÓN: EL USO DEL CONCRETO EN OBRAS DE LE CORBUSIER
}

FROM SIMULACRUM TO SIMULATE: THE USE OF CONCRETE IN LE CORBUSIER'S WORKS

\section{KISHI, SUNAO}

Mestre em Arquitetura e Urbanismo, Universidade Presbiteriana Mackenzie. E-mail: sunao.kishi@mackenzie.br

\section{OLIVEIRA, LUCIANA MONZILLO DE}

Doutora em Arquitetura e Urbanismo, Universidade Presbiteriana Mackenzie e Fundação Armando Álvares Penteado. E-mail: luciana.oliveira@mackenzie.br

\begin{abstract}
RESUMO
O concreto despontou com força ampla na arquitetura, a partir do final do século XIX e neste pouco mais de um século tem sido explorado como elemento estrutural das edificações, ao mesmo tempo em que ganhou destaque pelas suas características visuais. Assim, o concreto passou no século XX, de material simulacro da pedra natural, para material simulado. Para identificar como se desenvolveu esse fenômeno, a pesquisa apresenta sete obras construídas por Le Corbusier, no período entre os anos de 1923 e 1963. Os procedimentos da pesquisa fundamentam-se na identificação e definição dos termos simulacro, simulante e simulado; na análise crítica dos dados obtidos nos textos de diferentes autores; nos textos de autoria do próprio Le Corbusier; e na observação in loco de seis das sete edificações apresentadas. Os dados analisados na investigação permitiram identificar quatro fases na utilização dos diferentes aspectos visuais das superfícies de concreto armado das edificações e que estão diretamente relacionadas com a trajetória pessoal de Le Corbusier, suas motivações e premissas, e com a contextualização temporal e local das diferentes obras. Os resultados da pesquisa auxiliam a compreensão e exposição das diferentes e inovadoras técnicas empregadas por Le Corbusier para as superficies do concreto, o que reforça e amplia o seu repertório especulativo na manipulação do material, além do béton brut, que é inevitavelmente associado ao seu nome.

PALAVRAS-CHAVE: concreto; Le Corbusier; simulacro.
\end{abstract}

\section{RESUMEN}

El concreto despuntó con fuerza amplia en la arquitectura, a partir del final del siglo XIX y en poco más de un siglo ha sido explorado como elemento estructural de las edificaciones, al mismo tiempo que ha ganado destaque por sus características visuales. Así, el concreto pasó en el siglo XX, de material simulacro de la piedra natural, para material simulado. Para identificar cómo se desarrolló ese fenómeno, la investigación presenta siete obras construidas por Le Corbusier, en el período entre los años 1923 y 1963. Los procedimientos de investigación se basan en la identificación y definición de los términos simulacro, simulante y simulado; en el análisis crítico de los datos obtenidos en los textos de diferentes autores; en los textos de autoría del propio Le Corbusier; y en la observación in loco de seis de las siete edificaciones presentadas. Los datos analizados en la investigación permitieron identificar cuatro fases en la utilización de los diferentes aspectos visuales de las superficies de hormigón armado de las edificaciones y que están directamente relacionadas con la trayectoria personal de Le Corbusier, sus motivaciones y premisas, y con la contextualización temporal y local de las diferentes obras. Los resultados de la investigación auxilian la comprensión y exposición de las diferentes e innovadoras técnicas empleadas por Le Corbusier para las superficies del concreto, lo que refuerza y amplía su repertorio especulativo en la manipulación del material, además del béton brut, que es inevitablemente asociado a su nombre.

PALABRAS CLAVES: concreto; Le Corbusier, simulacro.

\section{ABSTRACT}

Concrete has emerged with great force in architecture since the end of 19th century and in just over one century it has been explored as buildings' structural element, at the same time it has gained prominence for its visual characteristics. Thus, the concrete passed in the twentieth century, from simulacrum material of natural stone, to simulated material. In order to identify how this phenomenon developed, the research presents seven Le Corbusier's buildings, from the period between 1923 and 1963. The research procedures are based on the identification and definition of the terms simulacrum, simulation and simulated; in the critical analysis of the data obtained in the different authors' texts; in Le Corbusier's texts; and on-site observation from six of the seven buildings presented. The data analyzed in the research allowed identifying four phases in different visual aspects use of buildings' reinforced concrete surfaces and how they are directly related to Le Corbusier's personal trajectory, his motivations and premises, and the temporal and local contextualization of the different works. The results of the research help the understanding and exposition of different and innovative techniques used by Le Corbusier for the surfaces of the concrete, which reinforces and expands his speculative repertoire in the manipulation of the material, besides the béton brut, which is inevitably associated with his name.

KEYWORDS: concrete; Le Corbusier; simulacrum.

\section{INTRODUÇÃO}

A pesquisa surge da observação do cenário atual da arquitetura em que o concreto vem sendo simulado por diferentes materiais empregados na construção civil, principalmente no setor de revestimentos, tanto em ambientes internos, como para uso externo. A simulação tem acontecido principalmente por seu aspecto 
visual, e não por sua função como material estrutural. Assim, no século $X X$ o concreto passou de material simulacro da pedra natural, para material simulado; pesquisar este percurso de valorização do concreto armado é o objetivo desta investigação.

O termo simulacro é utilizado em várias áreas do conhecimento e, no caso específico dos materiais de construção, quando um material simulante ${ }^{1}$ procura substituir o seu simulado em uma situação verossímil, a sua condição é de simulacro. Enquanto simulacro, um material simulante deve manter as funções físicas do seu simulado, podendo ou não esconder a verdadeira identidade material ou ainda, podendo superar o simulado (KISHI, 1998).

Simulacro etimologicamente surge a partir dos termos do latim simulare, simulação; insimulation-onu, simular, aparentar, disfarçar; e simulacrum-i, falsificação, imitação (CUNHA, 1982). Para Baudrillard (1991, p. 9), simular está relacionado com ausência: "Dissimular é fingir não ter o que se tem. Simular é fingir ter o que não se tem. O primeiro refere-se a uma presença, o segundo a uma ausência".

Aceita-se como simulante o material que guarda verossimilhança com o material simulado, estando o primeiro numa condição ativa e o segundo numa condição passiva. Segundo Lalande (1996), verossimilhança é a qualidade ou caráter de verossímil, que parece verdadeiro.

Quando o material simulante conserva proximidade com o verdadeiro, isto é, com o material que foi simulado, existe verossimilhança; quando o material simulante conserva apenas algumas características do material simulado, existe semelhança. Sob a perspectiva da Semiótica, quando um material está no lugar de outro e procura substitui-lo numa situação verossímil, assume a condição de simulacro. O simulacro apoia-se na verossimilhança.

Visualmente, no material simulante valorizam-se primordialmente as qualidades aparentes do respectivo simulado. Isso contribui para a formação do gosto e, consequentemente, para a aceitação dos simulantes junto ao consumidor. Entretanto, o material simulante pode não "assumir" a aparência do material simulado. No caso de instalações hidráulicas feitas com tubos de PVC, o simulante não assume a aparência do simulado (o cano metálico), mas conserva a funcionalidade essencial do produto (o tubo de instalação hidráulica), embora isso possa não aparecer exteriormente.

O material simulante pode ser classificado conforme o seu nível de verossimilhança em relação ao material verdadeiro (pedra, cerâmica, madeira, ferro, etc.). Para constatar o nível de verossimilhança deve-se avaliar a função física do simulante a partir da observação visual, tátil e sonora, entre outras.

O nível de verossimilhança está ligado ao tipo de matéria-prima que se usa na fabricação do simulante, que pode ser feito do material verdadeiro transformado ou de material artificial. Por exemplo: o carpete de madeira que simula o assoalho de tábua pode ser feito de madeira laminada ou de resina melamina. No primeiro caso, o simulante guarda um nível maior de verossimilhança em relação ao simulado.

A simulação de materiais de construção e a sua aplicação na Arquitetura acontece com ênfase a partir do modernismo, podendo ser exemplificado pelo concreto, material que foi visto durante muito tempo somente como pedra artificial e cuja linguagem própria passa a ser explorada a partir do início do século XX.

É a partir de sua função física que o concreto armado (concreto + aço) deixa de ser visto apenas como material simulante da pedra e passa a ter significado como elemento arquitetônico, com linguagem própria. Desse modo, como afirma Banham (1975), o concreto armado assume a identidade de material tipicamente modernista.

Para identificar como se desenvolveu a evolução na aplicação do concreto armado na arquitetura, desde um material simulante até um material a ser simulado por suas características visuais, a pesquisa utiliza da análise de sete obras construídas por Le Corbusier, representante da arquitetura moderna, e responsável pelo emprego e disseminação das virtudes estruturais e plásticas do concreto.

A seleção das obras envolveu um cruzamento entre a linha cronológica das diferentes edificações, perpassando quatro décadas de história entre os anos de 1923 e 1963, com relação aos diferentes aspectos visuais empregados no uso do concreto.

\section{CONCRETO}

Inicialmente as pedras naturais foram utilizadas nos templos da Antiguidade, principalmente na Grécia, com o método de construção baseado no encaixe, sem utilização de qualquer tipo de argamassa. Explorava-se a beleza dos mármores, com seus cristais brilhantes, mas os apoios deviam ser posicionados muito próximos, pois a pedra utilizada como elemento portante horizontal não resiste ao efeito da flexão. 
Os romanos aprenderam a utilizar duas misturas que teriam papel fundamental na construção: a argamassa e o concreto, ambos feitos com o cimento fabricado a partir da calcinação do calcário até a obtenção da cal, que quando misturado à água, forma uma pasta que enrijece ao secar. A argamassa resultante da mistura do cimento, areia e água, servia para fixar as pedras ou os tijolos uns aos outros. O concreto era considerado uma espécie de pedra artificial e era feito a partir de uma mistura de cinzas vulcânicas, cal, areia, cascalho e água, e permitia a construção de arcos e posteriormente de abóbadas (MARCHAND, 1995).

Segundo Botelho (2011), a pedra natural como material utilizado nas construções tem vantagens como: a enorme durabilidade, a resistência à compressão, e pode ser encontrada em muitos lugares. Mas, como apresenta dificuldades para ser cortada e esculpida no formato desejado, é um material que exige maior tempo para execução de edifícios.

O concreto, por sua vez, é considerado o material que permite superar essas dificuldades inerentes ao uso da pedra na construção. Botelho define o concreto como "pedra artificial, constituída da mistura de pedras de um ou dois tamanhos, areia, cimento e água. Tem boa resistência à compressão e fraca resistência à tração. Tem a grande vantagem de ser moldável na forma que se queira, usando-se para isso as fôrmas" (BOTELHO, 2011, p. 19).

A capacidade de ser um material moldável foi um dos aspectos que incentivou o uso do concreto nas edificações. Segundo Giedion (2004), em 1824, Joseph Aspdin começou a utilizar o cimento Portland como imitação da pedra, e este foi considerado o primeiro aglutinador hidráulico, que endurece em contato com a água. A pedra calcária e a argila, processadas e transformadas em pó, quando misturadas à água aglomeravam-se adquirindo dureza, coloração, textura e forma de pedra. A adição de agregados de várias granulometrias ao cimento fazia surgir o concreto, material simulante da pedra. Ao identificar o cimento como imitação da pedra, Joseph Aspdin referia-se ao aspecto funcional, estrutural, aparência visual, trabalhabilidade, resistência, textura e coloração.

A partir desse momento, apareceram utilizações pioneiras do uso do concreto que despontariam no sistema do concreto armado como é utilizado hoje. Em 1868, o jardineiro Monnier introduz uma malha de arame para reforçar as floreiras de concreto. Na sequência, François Hennebique, na França e Ernest Leslie Ransome, na América do Norte, passaram a utilizar proporções de ferro e concreto, adequando às exigências de resistência do concreto armado (GIEDION, 2004).

A introdução do concreto armado na Arquitetura com valorização da linguagem do material pode ser atribuída a Auguste Perret e Gustave Perret, em 1903, no projeto e construção do edifício na Rua Franklin, 25 bis, em Paris. Mas foi um discípulo de Perret, Le Corbusier, o grande responsável pelo emprego e disseminação das virtudes estruturais e plásticas do concreto.

Le Corbusier pode ser considerado o personagem principal da alteração do concreto de um material simulacro para um material simulado. Através do desenvolvimento de suas obras é possível identificar esta transformação em quatro fases, que estão relacionadas com sua visão sobre a arquitetura, os conceitos que elaborou e colocou em prática, as experimentações que desenvolveu no uso do concreto, e as dificuldades que encontrou no decurso de sua vida profissional. Para identificar como se desenvolveu esse fenômeno no emprego do concreto, de material simulacro para material simulado, a pesquisa utiliza da análise de sete obras construídas por Le Corbusier. A seleção das obras envolveu um cruzamento entre a linha cronológica das diferentes edificações, perpassando quatro décadas de história entre os anos de 1923 e 1963, com relação aos diferentes aspectos visuais empregados no uso do concreto. A análise deste seleto grupo de obras ilustra as quatro fases identificadas na aparência visual no uso do concreto armado por Le Corbusier: o purismo do concreto revestido de branco; o concreto como material autêntico; o concreto bruto (béton brut); e o concreto aparente refinado.

\section{0 purismo do concreto revestido de branco}

Em 1907, Le Corbusier, então com 20 anos de idade, faz uma viagem por Pisa, Siena, Florença e Veneza, quando, segundo Cohen $(2007$, p.8) "dedica-se a quebrar os mistérios da linguagem das pedras". No ano seguinte foi para Paris, onde o designer de cartazes, Eugène Grasset comenta sobre os experimentos com cimento armado dos irmãos Perret. Em março de 1908, após mostrar seus desenhos e croquis, Le Corbusier foi admitido no escritório de Auguste Perret (1874-1954), onde trabalhou por quinze meses (COHEN, 2007). Neste período teve a oportunidade de estudar os fundamentos da técnica de construção com emprego do concreto armado, fato este que influenciaria profundamente sua trajetória profissional: "A construção de concreto armado determinou uma revolução na estética da construção" (LE CORBUSIER, 1973, p. 39). 
Em 1911, com 24 anos de idade, Le Corbusier fez uma viagem pelos países dos Balcãs, Ásia Menor, Itália e Grécia, permanecendo por seis semanas na Acrópole, fazendo anotações e esboços por todo o trajeto, e que foram publicados dois anos depois. Nesta viagem, o conjunto de residências brancas mediterrâneas das ilhas gregas despertou o interesse de Le Corbusier pelo processo da caiação das construções.

O leite de cal está vinculado à moradia do homem desde o nascimento da humanidade; calcinam-se pedras, trituram-se, diluem-se com água e as paredes ficam do mais puro branco; um branco extraordinariamente belo [...] O leite de cal é a riqueza do pobre e do rico, de todo o mundo, como o pão, o leite e a água são a riqueza do escravo e do rei (LE CORBUSIER, 1996, p. 192 e 193).

Segundo Gardiner (1977), Le Corbusier ficou encantado com a pureza do branco, e este acabou se transformando no vínculo de suas primeiras obras, assim como dos movimentos arquitetônicos dos anos 1920 e 1930.

O uso da caiação como tema principal numa arquitetura onde todos os elementos eram inteiramente originais e inesperados foi mais uma das invenções de Le Corbusier, e um dos muitos fatores que the deram a condição de líder da moderna arquitetura europeia. (GARDINER, 1977, p. 42).

Le Corbusier também viajou pelos centros urbanos onde vivenciou as inovações da arte moderna, em Paris, Berlim e Viena:

Em suas viagens às principais capitais captou por sua vez as ideias racionalistas e se sentiu solidário com a orientação para um classicismo abstrato em prejuízo tanto do historicismo do século XIX como dos aspectos mais floridos do Art Nouveau (CURTIS, 1987, p.13)

Em 1914, como resposta para a destruição das áreas francesas que foram invadidas durante a Primeira Guerra Mundial, Le Corbusier juntamente com o engenheiro Max du Bois, propôs um sistema estrutural para edificações de baixo custo, a partir de uma estrutura independente de concreto armado que foi denominada Dom-ino, da junção das palavras domus - casa e innovatio - inovação (COHEN, 2007).

Partindo desses dois princípios: o sistema estrutural independente de concreto armado e o revestimento externo da edificação com caiação, Le Corbusier construiu algumas residências, nesse período entre os anos 1920 e 1930, entre elas: a Vila La Roche-Jeanneret e a Vila Savoye.

No projeto para as residências geminadas para Raoul La Roche e Albert Jeanneret em Auteuil, bairro burguês de Paris, Le Corbusier teve que seguir as restrições que determinavam o uso do terreno, além da orientação da face principal do lote voltada para o norte.

As residências possuem três pavimentos, sendo que na residência La Roche, Le Corbusier liberou o pavimento térreo elevando sobre pilotis os dois pavimentos superiores, criando assim uma proteção coberta para a entrada principal (Figuras 1 e 2).

Toda a parte externa, tanto estrutura como vedações são pintadas de branco, em contraposição a alguns dos ambientes interiores que tem as superfícies coloridas. É o caso, por exemplo, da galeria de pinturas que ocupa o primeiro e segundo pavimentos, com uma rampa lateral de acesso entre os dois níveis, e onde as paredes têm diferentes cores, assim como o guarda-corpo da rampa. As residências não apresentam elementos em concreto aparente:

Se a casa é totalmente branca, o desenho das coisas nela se destaca sem transgressão possível; nela o volume das coisas aparece nitidamente; nela a cor das coisas é categórica. O branco de cal é absoluto, tudo nele se destaca, escreve-se absolutamente, preto no branco; é franco e leal. (LE CORBUSIER, 1996, p. 193).

Atualmente as residências são ocupadas pela Fundação Le Corbusier, uma vez que o amigo e proprietário Raoul La Roche doou a sua casa para a Fundação Le Corbusier, que em seguida conseguiu anexar à antiga residência de Albert Jeanneret. 
Kishi, S.; Oliveira, L. M.

Figura 1: Vista externa das residências da Vila La RocheJeanneret, Paris, França, 1923.

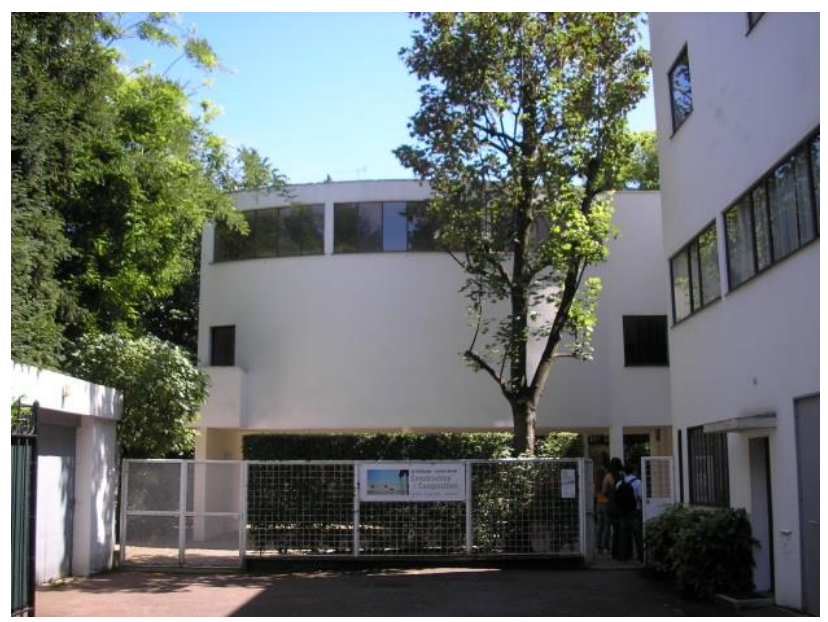

Fonte: Acervo dos autores, 2007.
Figura 2: Pilotis do pavimento térreo da residência La Roche, com revestimento em pintura branca, Paris, França, 1923.

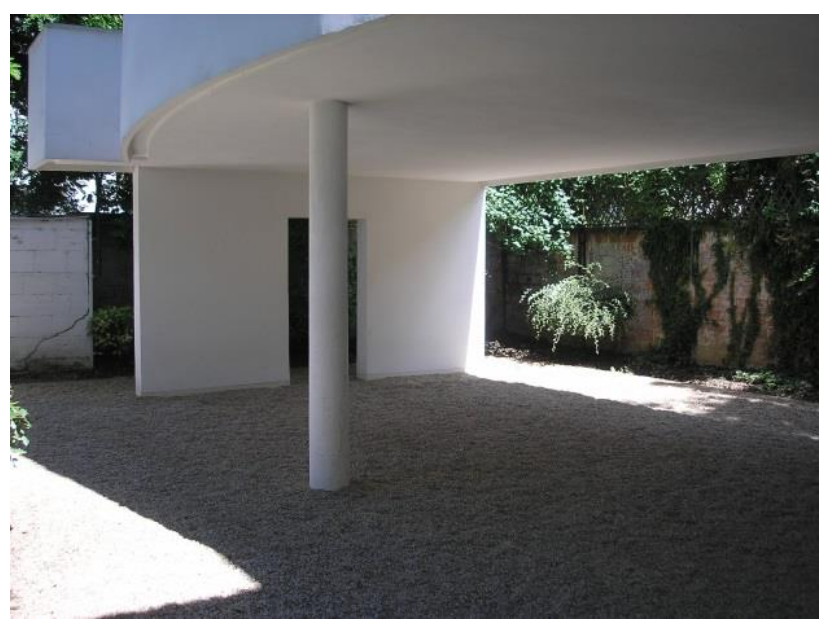

Fonte: Acervo dos autores, 2007.

Alguns anos após concluir a Vila La Roche-Jeanneret, Le Corbusier projetou a Vila Savoye (1928-1931). A residência é um exemplo da aplicação dos "cinco pontos" para uma arquitetura, que havia formulado em 1927, pois apresenta: pilotis, estrutura independente, planta livre, janelas em fita e o terraço-jardim (COHEN, 2007). No pavimento térreo, a construção semicircular fechada é o acesso à rampa e à escada que conectam com o pavimento superior, ficando as dependências de serviço na parte sul, e a área entre os pilotis sendo parcialmente utilizada para o estacionamento de automóveis. Os elementos estruturais da residência estão aparentes enquanto forma, volume e vedação, mas todos estão uniformizados em sua expressão visual, pela adoção da cor branca (Figuras 3 e 4).

Figura 3: Detalhe dos pilotis, viga e laje do pavimento térreo, pintados de branco na Vila Savoye, Poissy, França, 1928-1931.

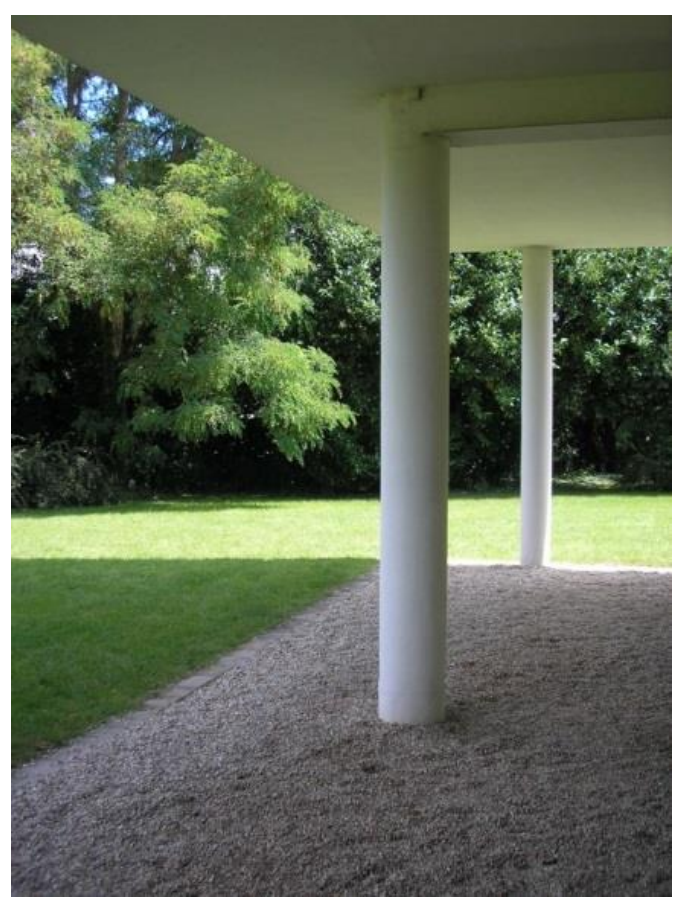

Fonte: Acervo dos autores, 2007.
Figura 4: Vista das fachadas leste e norte da Vila Savoye, Rue de Villiers, Poissy, França, 1928-1931.

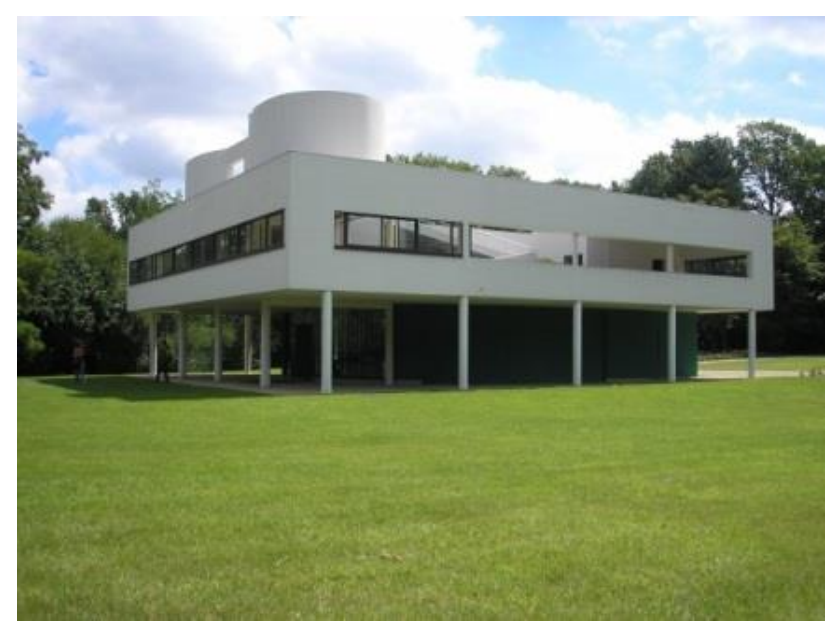

Fonte: Acervo dos autores, 2007.

\section{Concreto como material autêntico}

Segundo Cohen (2007), o projeto da casa de fim-de-semana para o segurador Pierre Savoye, em Poissy, é considerada como o fim do ciclo das residências da fase purista de Le Corbusier. A partir de então, ele 
começou a empregar o concreto armado sem revestimento ou coloração de superfície, e passou a utilizar composições de elementos pré-fabricados, também com a aparência autêntica do material, como nos casos do Pavilhão Suíço e a Unidade de Habitação de Marselha.

O Pavilhão Suíço (1929-1933) faz parte do complexo da Cidade Universitária de Paris (1921) e tem por objetivo alojar os estudantes estrangeiros e fornecer alguns serviços. O projeto foi desenvolvido em parceria com Pierre Jeanneret, seu primo, e iniciou-se em 1929, mas a construção perdurou de 1931 a 1933, devido a alguns problemas econômicos.

O conjunto é composto por três volumes: o bloco maior, com os apartamentos; o bloco intermediário que contém a circulação vertical; e o volume mais baixo, em formato curvo, que contém o saguão de acesso, o alojamento do porteiro, cozinha, refeitório e as áreas de serviço. Neste bloco, Le Corbusier utiliza o fechamento da parede curva em pedra, "de maneira rústica e irregular de forma a marcar um agudo contraste com o vidro e o acabamento liso da principal edificação” (GARDINER, 1977, p. 64).

O processo construtivo propôs a industrialização do canteiro de obras e a utilização de elementos da construção produzidos em série. O pavimento térreo é composto por seis conjuntos de pilares duplos e vigas de concreto armado aparente. Sobre este conjunto de pilotis, ergue-se um bloco de três pavimentos, com 15 apartamentos por andar, e um terraço-jardim na cobertura. O bloco superior é composto por uma malha de pilares e vigas metálicas, que compõe a estrutura de sustentação das vedações (Figuras 5 e 6).

Figura 5: Pilares e vigas de concreto aparente do pavimento térreo do bloco dos dormitórios do Pavilhão Suíço da Cidade Universitária de Paris, 1929-1933.

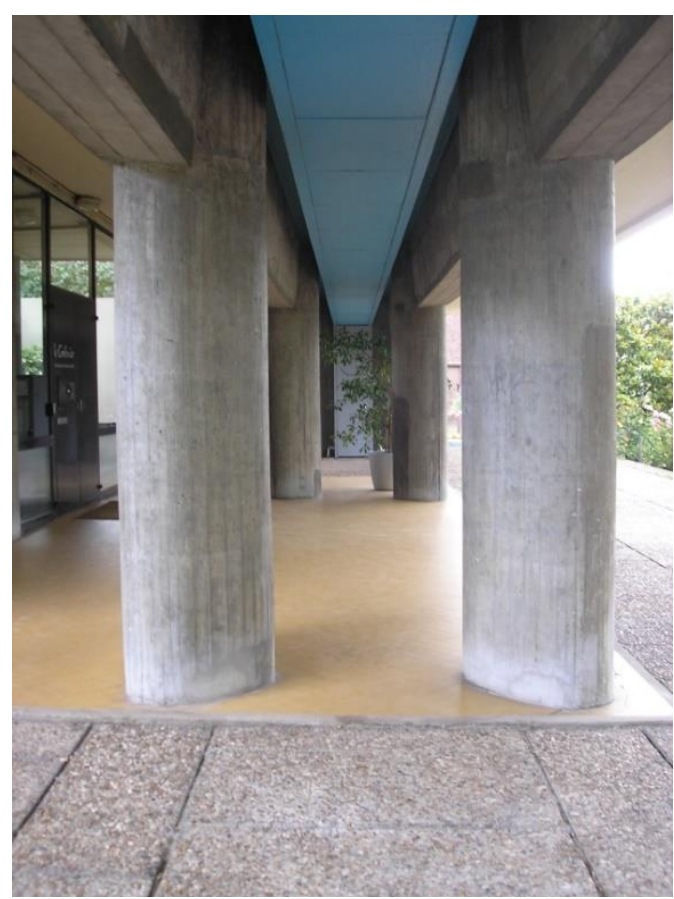

Fonte: Acervo dos autores, 2007.
Figura 6: Vista da fachada norte, com poucas aberturas para iluminação das circulações horizontais de acesso aos apartamentos, e à frente, o bloco da circulação vertical, com uma empena cega, composta por painéis pré-fabricados, no Pavilhão

Suíço da Cidade Universitária de Paris, Boulevard Jourdan, 1929-1933.

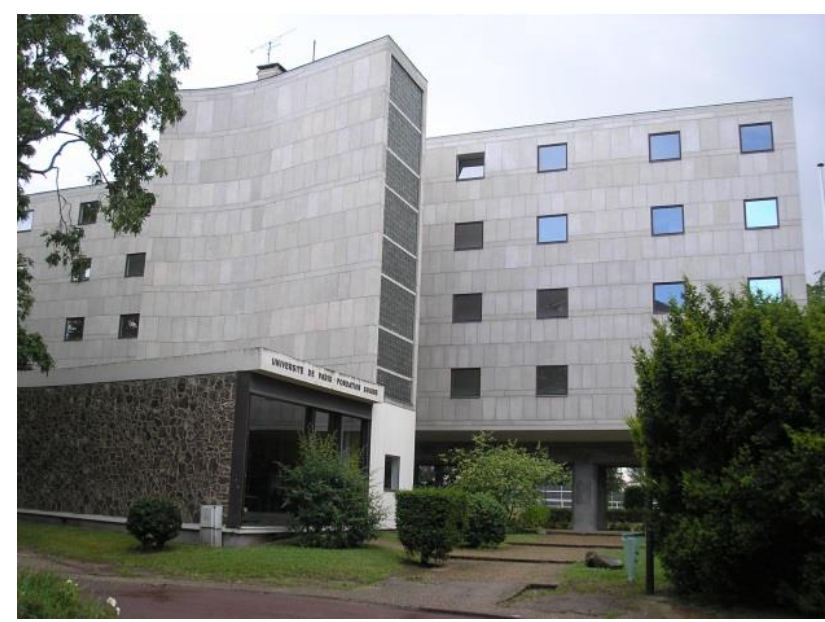

Fonte: Acervo dos autores, 2007.

\section{Concreto bruto (béton brut)}

O edifício multifuncional denominado de Unidade de Habitação de Marselha (1946-1952) foi o primeiro projeto solicitado pelo Estado francês ao escritório de Le Corbusier, e tinha por objetivo fornecer moradia às famílias desalojadas após o término da guerra, período marcado pela escassez de dinheiro, aço e mão-de-obra especializada.

O projeto da Unidade de Habitação de Marselha consiste de um bloco com 18 pavimentos e 337 apartamentos dúplex de dimensões variadas, para apenas um morador, até famílias com oito pessoas. Além dos apartamentos para moradia fixa, o complexo também conta com acomodações de um hotel com restaurante, lojas comerciais e estúdios profissionais, e na cobertura, uma creche e sala de jogos, parquinho, piscina 
infantil, teatro e solário. Todo o conjunto está suspenso sobre espessos pilotis que foram projetados para conter as redes de abastecimento e coleta de águas pluviais.

O edifício possui estrutura de concreto armado, onde cada célula habitacional foi construída com painéis e brise-soleil pré-fabricados de concreto (SUMA, 2011). É então, justamente neste momento das dificuldades de um período pós-guerra que Le Corbusier é obrigado a substituir o material das fôrmas de moldagem da estrutura de concreto:

[...] sob a pressão de circunstâncias políticas e econômicas, que o obrigaram a abandonar sua armadura de aço do projeto original da "Unité", reagiu com sua habitual originalidade e agudo sentido do caráter da época e decidiu admitir que o concreto dá vida à forma a seu modo, por seu caráter de aglomerado de matérias pulverizadas que se vertem em fôrmas de madeira que, na França, adquirem raramente, pelas humanas eventualidades, a perfeição de uma cerca de jardim (BANHAM, 1966, p. 16).

A substituição das fôrmas de aço pelas fôrmas de madeira, juntamente com a utilização de mão de obra local menos especializada, foi considerada "uma revolução dentro da própria obra do mestre", segundo O'BYRNE OROZCO (2015, p. 290). A textura áspera das superfícies foi então denominada de concreto bruto:

[...] Essas limitações e condições sugeriam uma nova espécie de imagem para o concreto, que ele chamou béton brut, e brut, traduzido, significa bruto, grosseiro. Assim, béton brut [...] descreveu a impressão exata deixada no concreto pelas fôrmas de tábuas - as linhas das pranchas e seus respectivos veios - e essa impressão era, como tal, uma representação precisa de materiais naturais. Essa configuração rústica deu à edificação uma textura de qualidade primitiva, natural e calorosa, que bem se harmoniza com os métodos de construção mediterrâneos locais, quando em combinação com as cores vivas que Le Corbusier usou nos balcões e com o brilho do sol contra a paisagem agreste (GARDINER, 1977, p. 77)

Com os conhecimentos adquiridos no enfrentamento das dificuldades de execução das obras na Unidade de Habitação de Marselha, e a partir dos resultados visuais obtidos na rusticidade das superfícies de concreto, Le Corbusier empreendeu outros projetos em que utilizou estes recursos, principalmente na Índia e na Capela Notre-Dame-du-Haut, de Ronchamp.

Figura 7: Fachada sul da Capela de Notre-Dame-du-Haut, Ronchamp, França, 1950-1955.

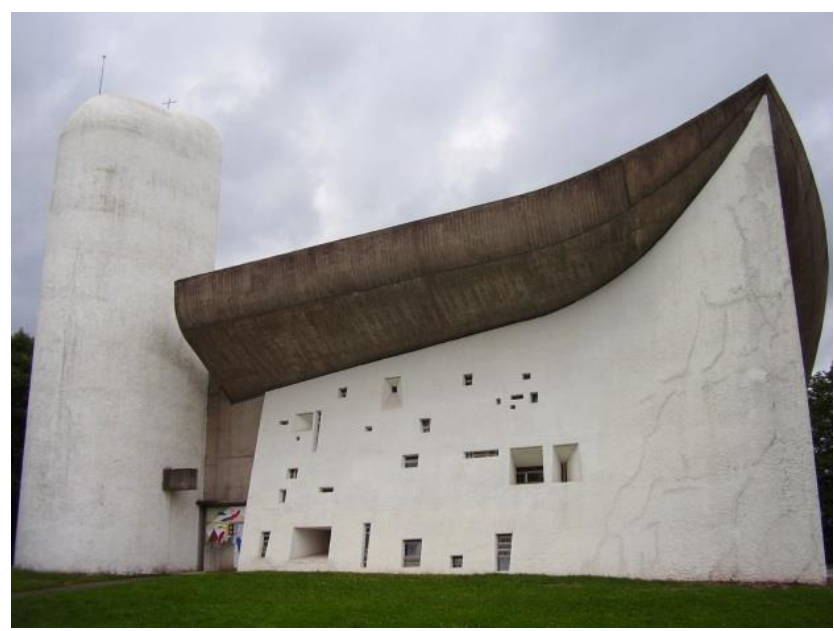

Fonte: Acervo dos autores, 2007.
Figura 8: Contraste entre a cobertura e o pilar de concreto aparente bruto, e a superfície pintada de branco da fachada leste da Capela de Notre-Dame-du-Haut, Ronchamp, 19501955.

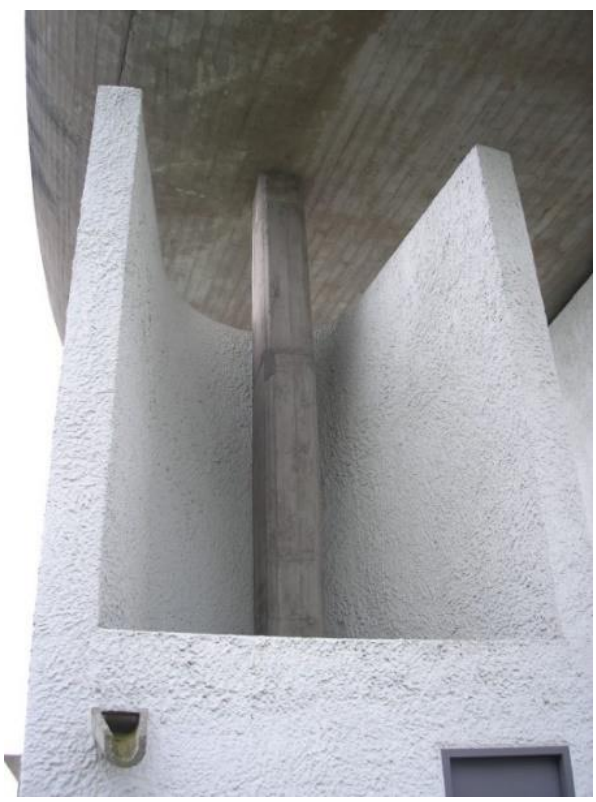

Fonte: Acervo dos autores, 2007. 
A capela Notre-Dame-du-Haut (1951-1955), localizada na colina de Bourlémont, a 500 metros de altitude, partiu da intenção de realizar um projeto específico para o local, sua história, e vinculado à paisagem do entorno.

Em junho de 1950, Le Corbusier visitou o terreno, onde os destroços da capela anterior, destruída pelo bombardeio da Guerra ainda permaneciam no local, e assim como havia ocorrido no projeto da Unidade de Habitação de Marselha, identificou a dificuldade que seria transportar o material da obra e utilizar a mão-deobra local:

[...] passei três horas a conhecer o terreno e os horizontes, de modo a ficar permeado com eles. A capela, explodida em pedaços, ainda está presente [...] Eu faço perguntas. Não existe uma estrada viável para transporte até o topo da colina. Consequentemente, eu devo ter que erguer a obra com areia e cimento. Provavelmente as pedras da ruína, rachadas pela geada e calcinadas pelo fogo, poderiam ser usadas como preenchimento, mas não para suportar cargas. (JEANNERET-GRIS, 1957, p. 88)

Além dessas premissas específicas, a ideia formal da cobertura da edificação também está associada com a forma da carapaça vazia de caranguejo, que Le Corbusier havia encontrado na praia de Long Island, em Nova York, em 1946.

A cobertura foi desenvolvida baseada no conceito da asa de avião, com a forma resolvida por duas lajes de concreto de seis centímetros de espessura cada uma, separadas a uma distância de 2,26 metros e sustentadas por sete vigas de 17 centímetros de espessura. Esta cobertura de casca de concreto de dupla superfície está apoiada em estreitos pilares e afastada das paredes por uma estreita fresta de 10 centímetros, por onde entra iluminação natural na capela (JEANNERET-GRIS, 1957).

As paredes que vedam a construção são espessas e feitas com as pedras recuperadas da antiga capela. Apenas na face sul é diferente, pois esta face é composta por pilares de concreto armado em formato triangular com 16 centímetros de espessura, e largura na base que varia de 1,40 metros até 3,70 metros, e com 50 centímetros de largura no topo. O fechamento entre pilares foi feito com duas membranas, uma interna e outra externa, de 4 centímetros de espessura cada uma, de concreto pulverizado sobre tela metálica expandida. A variação das distâncias entre as duas membranas, auxiliou na diferença de desenho das aberturas que compõem esta fachada.

O resultado final da edificação contrapõe a rusticidade da cobertura de concreto aparente, onde é possível identificar o desenho das lâminas de madeiras utilizadas nas fôrmas, com a brancura do revestimento das paredes e dos pilares de sustentação da cobertura (Figuras 7 e 8 ).

\section{Concreto aparente refinado}

Algumas das últimas obras de Le Corbusier foram construídas em países de outros continentes, com diferentes culturas, tradições, especializações técnicas e qualificação de mão-de-obra. Isto permitiu com que ele experimentasse outras técnicas de acabamento no emprego do concreto, como no caso do Museu Nacional de Arte Ocidental de Tóquio e o Centro de Artes Visuais Carpenter Center, em Massachusetts. Nos dois projetos, o concreto apresenta um refinamento visual:

A limpeza do concreto no Museu de Tóquio, ressaltado pelo próprio Le Corbusier, parece querer dar a entender aos japoneses, em particular, e a todo o mundo, em geral, que sua obra não é "brutalista” em si (O'BYRNE OROZCO,2015, p. 290).

O Museu Nacional de Arte Ocidental, em Tóquio, inaugurado em 1959, abriga o acervo da Coleção Matsukata de arte impressionista, composto por pinturas e esculturas que haviam sido confiscadas pelos franceses na Segunda Guerra Mundial e que foram restituídas posteriormente ao Japão. O projeto foi desenvolvido com o auxílio de Kunyo Maekawa e Junko Sakakura (BOESIGER, 1994).

O projeto inicial previa um conjunto formado pelo museu, um pavilhão de exposições temporárias, um teatro para 540 pessoas, e um anfiteatro a céu aberto, mas apenas o museu foi construído. 
A proposta para o museu é uma versão da espiral quadrada, que é a continuidade de um conceito já estudado por Le Corbusier desde 1929 para o Centro Cultural Mundial de Genebra, o Mundaneum, e depois desenvolvida no Museu de Crescimento llimitado, de 1939.

Trata-se de um edifício de três pavimentos, com o pavimento térreo em vedação de vidro recuado do alinhamento da fachada, deixando os pilotis de 53 centímetros de diâmetro em destaque. $O$ térreo abriga a entrada principal, guarda-volumes, loja, pequena biblioteca e acesso à primeira galeria de exposições. Esta galeria, por sua vez, compreende a área central da planta quadrada, com pé-direito duplo e um pilar de concreto aparente que sustenta a estrutura da cobertura de vidro. Todos os elementos estruturais de concreto aparente apresentam cuidadoso aspecto visual:

O museu será, em cada um de seus detalhes, uma maneira de mostrar como, a partir de uma tradição na construção em madeira como a que tem os japoneses, é possível alcançar a perfeição em um concreto que evoca, pela lisura das superfícies, a madeira que o deu a forma. O concreto deve poder expressar com sinceridade a maneira e as técnicas que o dão forma: quando não há mão de obra qualificada, sem dúvida, deve ser bruto, quando se conta com a mão de obra qualificada, deve ser fino. (O'BYRNE OROZCO,2015, p. 292).

À frente da fachada principal da edificação há uma escada externa para acesso direto ao primeiro pavimento, elevado sobre os pilotis de concreto aparente e que abriga as salas de exposições. Os quatro mezaninos correspondentes ao nível de um segundo pavimento, abrigam setores administrativos, área de convívio e pequenas exposições.

As vedações externas dos dois pavimentos superiores são compostas por quatro faixas de painéis de concreto pré-fabricados preenchidos com seixos verdes acinzentados. Esta solução foi considerada inédita na obra de Le Corbusier. Todos os painéis tem largura de 53 centímetros, e comprimentos de 226 centímetros na faixa inferior, 183 centímetros nas duas faixas centrais e 140 centímetros na faixa superior. Os painéis foram construídos em fôrmas colocadas sobre mesas vibrantes, com o concreto derramado sobre uma malha metálica, e com a face superior recoberta pelas pedras claras, colocadas uma a uma (O'BYRNE OROZCO,2015).

Figura 9: Vista da fachada sudoeste, a partir da rampa do acesso principal do Museu Nacional de Arte Ocidental, Tóquio, 1959.

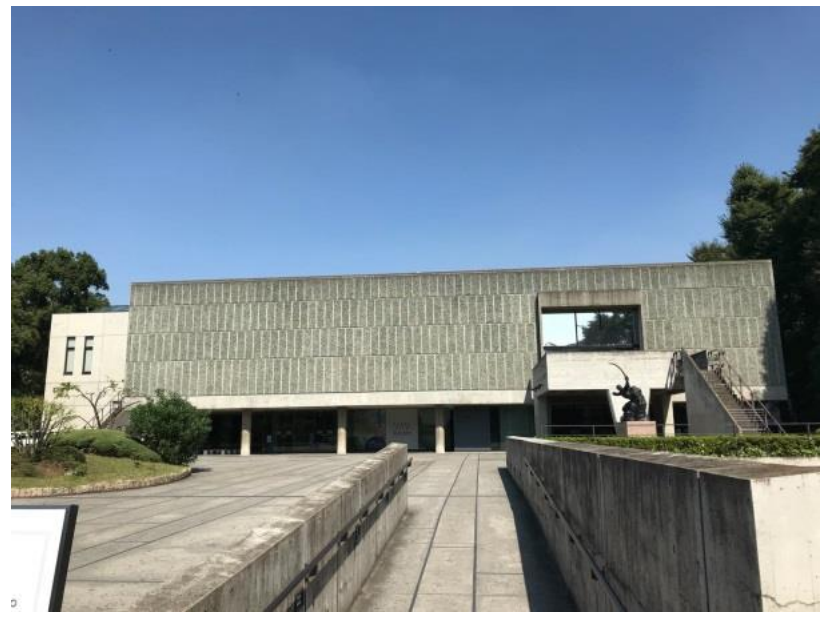

Fonte: Acervo dos autores, 2017.
Figura 10: Vista das fachadas noroeste e sudoeste do Museu Nacional de Arte Ocidental, Ueno-koen, Taito-ku, Tóquio, 1959.

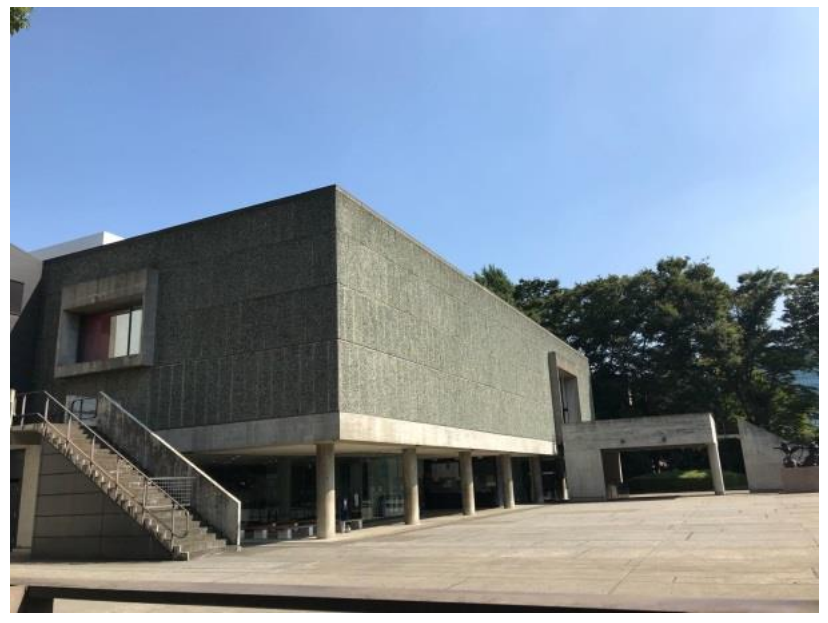

Fonte: Acervo dos autores, 2017.

Outro edifício em que Le Corbusier pôde utilizar dos recursos técnicos e da mão-de-obra especializada local foi o Centro de Artes Visuais Carpenter Center, inaugurado em 1963. O terreno destinado para implantação do edifício tem acesso por duas ruas paralelas, a Quincy St. e Precott St., e fica na área central da cidade universitária de Harvard, em Cambridge, Massachusetts.

A proposta para o projeto partiu de José Luis Sert, que havia trabalhado com Le Corbusier entre 1928 e 1930. O objetivo para o Centro de Artes Visuais era criar uma edificação para estimular os alunos da universidade 
de Harvard, que ao atravessarem este miolo de quadra, se instigassem a conhecer e a se inscrever para desenvolver trabalhos em diferentes campos das artes, como escultura, modelagem e maquete.

Le Corbusier utilizou o conceito de "passeio arquitetural" para projetar a transposição entre as duas ruas, criando uma rampa em forma de "S", que passa como um túnel no terceiro pavimento do edifício. O edifício composto por pavimento térreo, três pavimentos e terraço na cobertura, foi construído em concreto armado aparente, e a execução foi coordenada pelo próprio José Luis Sert. As fachadas da edificação apresentam diferentes formatos de brise-soleil de concreto (Figuras 11 e 12). Em contraposição ao concreto bruto utilizado na Unidade de Habitação de Marselha, neste edifício, várias superfícies foram polidas para dar um acabamento liso para o material, o que resultou em uma composição de superfícies de texturas suavizadas. (COHEN, 2007).

Figura 11: Vista do acesso à rampa em "S" do Centro de Artes Visuais Carpenter Center, Cambridge, Massachusetts, 19591962.

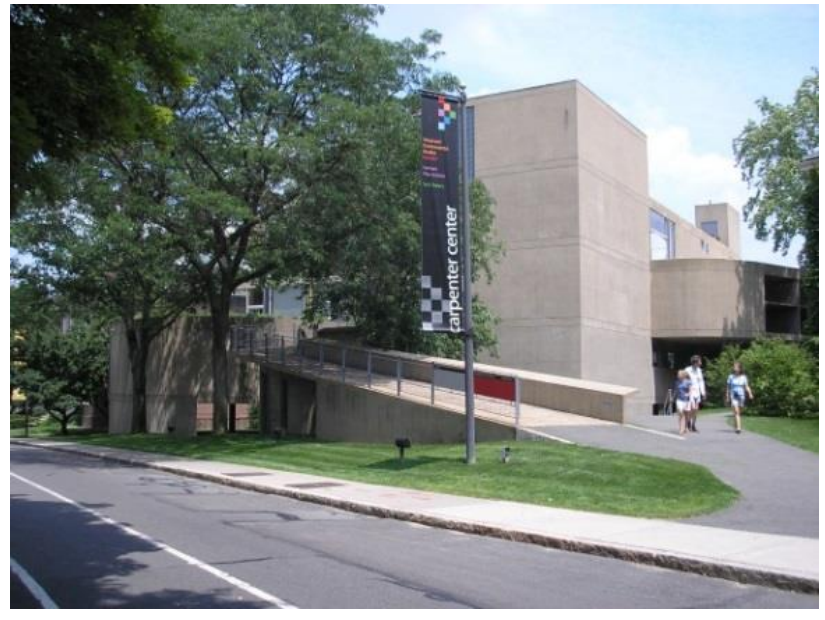

Fonte: Acervo dos autores, 2008.
Figura 12: Pilotis e brises-soleil de concreto aparente do Centro de Artes Visuais Carpenter Center, Cambridge, Massachusetts, 1959-1962.

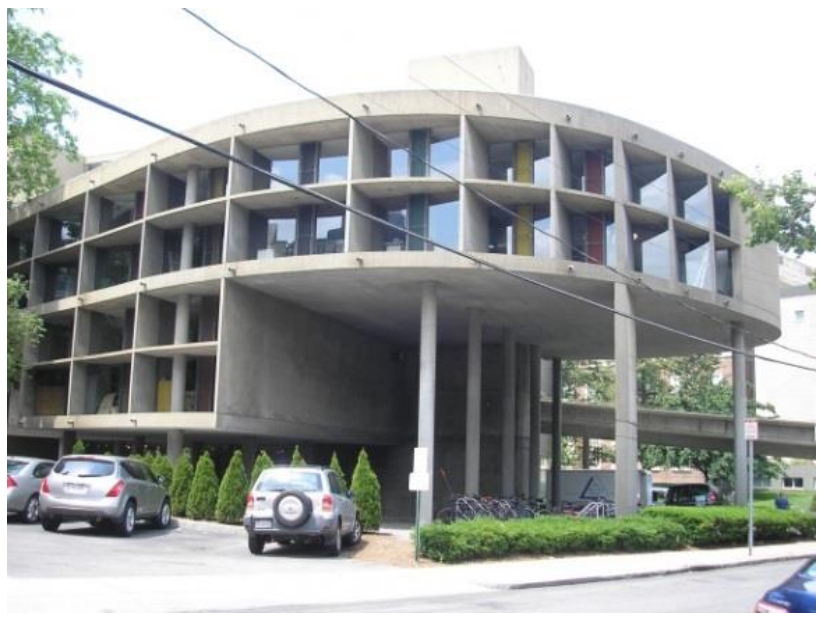

Fonte: Acervo dos autores, 2008.

\section{CONSIDERAÇÕES FINAIS}

Le Corbusier valorizou o concreto armado utilizando-o como elemento primário expressivo, através de uma linguagem arquitetônica revelada desde sua proposta para a Maison Dom-Ino. A plasticidade do material foi reconhecida pelos arquitetos e, desde então, o concreto armado é apreciado pela estética arquitetônica. Suas obras construídas exploraram diferentes modalidades e aparências visuais das superfícies de concreto.

Inicialmente, na fase em que Le Corbusier estava em busca da verdade estrutural das formas puras, 0 concreto comporta-se como um simulacro que substitui o simulado (pedra) em uma situação verossímil, superando as funções físicas do seu simulado, e escondendo a verdadeira identidade material sob o revestimento de cor branca.

Em suas fases posteriores, Le Corbusier empregou o concreto com sua verdadeira identidade material, ou seja, a estrutura de concreto e as placas de concreto pré-moldado foram utilizadas como material de visual autêntico. Nestas fases as diferenças estão relacionadas fundamentalmente com a maneira com que ele explorou as diferentes superfícies, que vão desde o grotesco visual do concreto bruto até o refinamento do polimento das superfícies, principalmente quando foi possível utilizar das técnicas e da mão-de-obra de outros países, como o Japão e Estados Unidos.

Portanto, uma vez superada a função física do simulado (pedra), o concreto adquiriu uma linguagem própria, afastando-se assim da condição de simulacro.

\section{REFERÊNCIAS}

BANHAM, R. El brutalismo em arquitectura. Barcelona, Gustavo Gili, 1996.

, R. Teoria e projeto na primeira era da máquina. São Paulo: Perspectiva, 1975.

BAUDRILLARD, J. Simulacros e simulações. Lisboa: Relógios d'Água, 1991. 
BOESIGER, W. Le Corbusier. São Paulo, Martins Fontes, 1994.

W. (Ed.). Le Corbusier: Oeuvre complète 1946-52. Zurique, Girsberger, 1953.

BOTELHO, M. H. C. Concreto armado eu te amo, para arquitetos. São Paulo: Blucher, 2011.

COHEN, J. Le Corbusier 1887-1965: Lirismo da Arquitectura da Era da Máquina. Singapura, Taschen, Paisagem, 2007. , J. O futuro da arquitetura desde 1889: uma história mundial. São Paulo: Cosac \& Naify, 2013.

CUNHA, A. G. Dicionário etimológico Nova Fronteira da língua portuguesa. 2. ed. Rio de Janeiro: Nova Fronteira, 1982. GARDINER, S. Le Corbusier. São Paulo, Cultrix, Ed. da Universidade de São Paulo, 1977.

GIEDION, S. Espaço, Tempo e Arquitetura. São Paulo, Martins Fontes, 2004.

JEANNERET-GRIS, C. The chapel at Ronchamp. London: Architectural Press, 1957.

KISHI, S. Simulacro do material: estudo do caso Shopping São Paulo Market Place. 1998. Dissertação (mestrado) Universidade Presbiteriana Mackenzie, São Paulo, 1998.

LALANDE, A. Vocabulário técnico e crítico da filosofia. 2.ed. São Paulo: Martins Fontes, 1996.

LE CORBUSIER. A arte decorativa. São Paulo: Martins Fontes, 1996.

. Por uma arquitetura. São Paulo: Perspectiva, 1973.

MARCHAND, P. (org.). A arte da construção. As origens do saber. São Paulo: Cia Melhoramentos, 1995.

O'BYRNE OROZCO, M. C. Le corbusier y la arquitectura instalada en su sitio: los museos de Ahmedabad y Tokio. Bogotá: Universidad de los Andes, 2015.

PATTON, W.J. Materiais de construção para Engenharia Civil. São Paulo, EDUSP, 1978, p.3.

SUMA, S. Le Corbusier. São Paulo, Folha de São Paulo, 2011.

\section{NOTAS}

${ }^{1}$ Embora a palavra "simulante" não esteja registada em dicionários de língua portuguesa no Portugal e no Brasil, nesse artigo optou por utilizá-la como neologismo, a fim de possibilitar a diferenciação dessa ideia de outros termos presentes no texto, como simulado e simulacro 